\title{
Preface to the Second Edition
}

In the midst of writing the revisions to this second edition of Applied Anthropology in Canada the report of the Ipperwash Inquiry was released by the Ontario government in May 2007. It was obvious to me that this large report, containing nearly 800 pages and 100 recommendations, was a highly relevant document for understanding contemporary Aboriginal matters. The Ipperwash Inquiry was primarily about the killing of Dudley George of the Stoney Point First Nation, but there were larger issues discussed pertaining to Aboriginal rights that need to be considered. It is for this reason that this second edition contains a rather extensive discussion of the Ipperwash Inquiry and its recommendations, especially as these relate to the earlier report of the Royal Commission on Aboriginal Peoples (RCAP), released in 1996. This new edition also has an updated list of references and an expanded discussion of research in Canadian applied anthropology relating to contemporary Aboriginal issues. As well, it focuses on such matters as an update to the changes in the Indian Act pertaining to Bill C-31 (1985) that relate to matters of First Nations employment, housing, identity issues, and other repercussions resulting from the drastically expanded population of status Aboriginal people. A more in-depth discussion of terminology relating to First Nations people is also included in this second edition, along with a more extended treatment of the history of anthropology in Canada from an applied perspective. In all, although much has changed in the twelve years since the first edition of this book appeared in 1995, the goal of studying Aboriginal issues from the perspective of applied anthropological research in Canada remains the same. Just as relevant today as ever are 
xiv Preface to the Second Edition

the challenges that academic disciplines such as anthropology face regarding the need to define more clearly what we really stand for, and to confront the oppression of indigenous peoples. 